\title{
Ultimate Transformerless Boost DC-DC Converter for Renewable Energy Applications
}

\author{
Omar Abdel-Rahim ${ }^{\square, 1}$, Esam H. Abdelhameed ${ }^{2}$
}

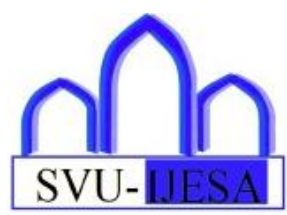

\begin{abstract}
In this article, a new high gain dc/dc converter is proposed that can be used with applications that require elevating output voltage to higher voltage-level such as PV applications. The proposed configuration is able to achieve high-voltage-gain, compared to any other transformerless topologies. The voltage stresses on the active MOSFETs are lower than half of the output voltage. Hence, low rated components are selected. The principles of operation of the two configurations are analyzed in details. Hardware prototype is implemented in the lab, in order to verify the analytical analysis of the topology.
\end{abstract}

Keywords: Ultimate boost dc/dc boost converter, low voltage stress, Renewable.

\section{Introduction}

Nowadays, dc/dc converters are existing in most of the industrial applications [1]-[2]. In case of applications such as photovoltaic (PV) energy systems, a step-up $\mathrm{dc} / \mathrm{dc}$ boost converter is mandatory to boost low voltage to high voltage to enable grid integration or supply power to an islanded load. In most of the practical cases, the converter is configured to generate output voltage around $400 \mathrm{~V}$ with input voltage ranges from 18 to $50 \mathrm{~V}$ only [3]-[5].

$\mathrm{DC} / \mathrm{dc}$ converters are classified into isolated and non-isolated topologies [6]-[8]. Ideally, the traditional boost converter is able to provide an infinite boosting ratio. However, practically, the step-up ability is limited and restricted by power devices parasitic components,

\footnotetext{
Received: 28 October 2021/ Accepted: 30 November 2021

$\square$ Corresponding Author Omar Abdel-Rahim, O.abdelrahim@aswu.edu.eg

1 Electrical Engineering Department, Faculty of Engineering, Aswan University

2 Electrical Engineering Department, Faculty of Energy Engineering, Aswan University
}

capacitance and inductance, and conduction losses caused by resistances and diodes voltage drops. Another limitation for having such very high step-up ratio is that triggering the power switch at high duty cycle may cause reverse recovery problems and magnetic saturation issues [9]-[12].

Non-isolated converters are preferred where low size and higher efficiency is important, however lack of isolation may cause safety issues. Non-isolated topologies could be categorized into coupled and non-coupled topologies [13]-[15].

Utilization of coupled inductors in some topologies added different benefits such as low stress of the switching devices, and improves the voltage gain of the converter, However, due to leakages, high voltage spikes are expected and make the utilization of clamping circuits are mandatory [16]-[18].

Non-coupled topologies reported in the literature use different approaches to achieve high voltage gain ability such as capacitor-diode voltage multiplier cell. Switched inductors/capacitors and cascading of two or more converters [19]-[21].

A class of high voltage gain converters have been reported in the literature called quadratic boost converters can generate high voltage gain without using extreme duty cycle, however with increase in the input power their efficiency is decreasing drastically [22]-[24].

$\mathrm{Z}$-source and its modified version which is so called quasi z-source are a type of non-isolated high gain boost converters, where the is replaced by an impedance network, main drawback is their restricted duty cycle operation [25]-[27].

Interleaved boost converters are used in high power applications where they provide better efficiency than boost converters in high power. The problem with interleaved converters is that a voltage boost circuit is needed at the end to increase the gain of the converter [28].

This manuscript presents a new dc/dc converter with 
high step-up ability to be used in renewable energy systems. The proposed topology has some distinct advantage such as high step-up capability, low voltage-stress on the active devices, and moderate-efficiency. The proposed configuration is convenient to PV applications or any other application that requires to elevate output voltage to a higher level and having continuous current drawn from the input side.

\section{Proposed High Step-Up Converter}

Configuration of the proposed converter is depicted in Fig.1. It consists of three-diodes, three-inductors, one-capacitor, and three-switches. The three switches and diode $D_{2}$ are triggered on and off simultaneously. The two other diodes are operating in a complementary manner to the switches. Inductors are charged when the switches are turned on and discharge their energy to the output load once switches are turned off. In the upcoming analysis, the small-ripple approximation is used. And, the converter is designed to operate in continuous conduction mode. Parameters are assumed to be ideal in the upcoming analysis, in order to ease the analysis of the converter. A graph of the ideal key waveforms of circuit devices are shown in Fig.2. The converter has two modes of operation depending on the switches are turned on or off.

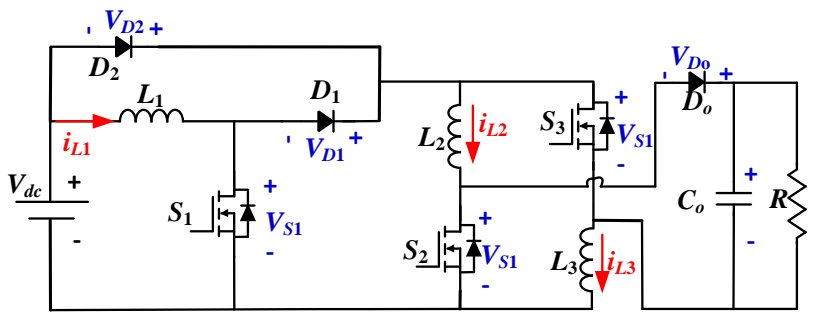

Fig.1. proposed configuration

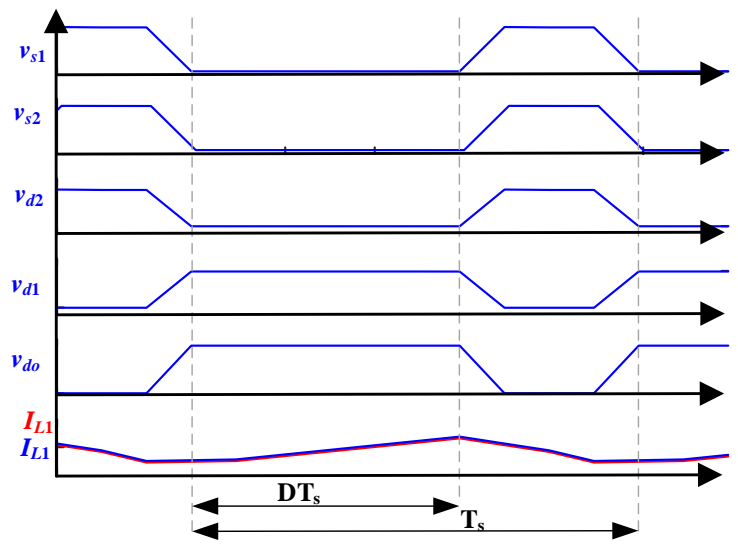

Fig.2. Ideal key waveforms.

\section{A. Mode I}

This mode is activated once the switches are turned on, the depiction of this mode is illustrated in Fig.3. The three switches and diode $D_{2}$ are turned on at the same time. In this mode inductor $L_{1}$ is charging from the input dc-source, and inductors $L_{2}$ and $L_{3}$ are charging from input dc-source. Diodes $D_{1}$ and $D_{o}$ are having reverse voltage and they are turned off. Output capacitor $C_{o}$ is discharging its energy to the load side. The characteristic equations that describe this mode of operation is as follows:

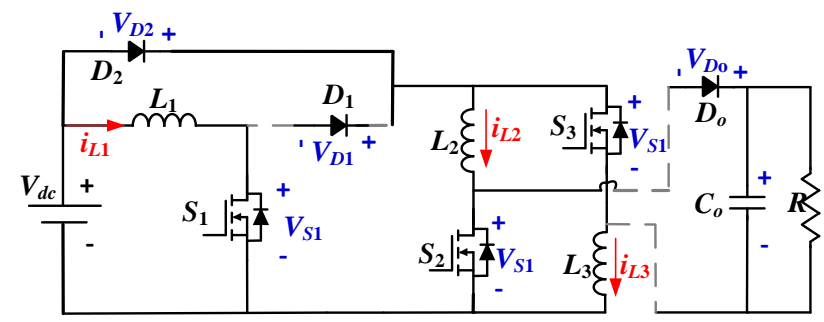

Fig.3. Configuration of Mode I.

$$
\left\{\begin{array}{c}
v_{L 1}(\mathrm{t})=v_{L 2}(\mathrm{t})=v_{L 3}(\mathrm{t})=V_{i n} \\
i_{c o}(\mathrm{t})=-V_{o} / R
\end{array}\right.
$$

\section{B. Mode II}

This mode is activated once the switches are turned off, the depiction of this mode is illustrated in Fig.4. The three switches are turned off at the same time. In this mode inductors $L_{1}, L_{2}$ and $L_{3}$ are discharging their energy into output load and output capacitor $C_{o}$. In order to keep a continuous path for the inductor currents, diodes $D_{1}$ and $D_{o}$ are working as a freewheeling diode and they are turned on. The characteristic equations that describe this mode of operation is as follows:

$$
\left\{\begin{array}{c}
v_{L 1}(\mathrm{t})=v_{L 2}(\mathrm{t})=v_{L 3}(\mathrm{t})=\left(V_{\text {in }}-V_{o}\right) / 3 \\
i_{c o}(\mathrm{t})=i_{L}-V_{o} / R
\end{array}\right.
$$

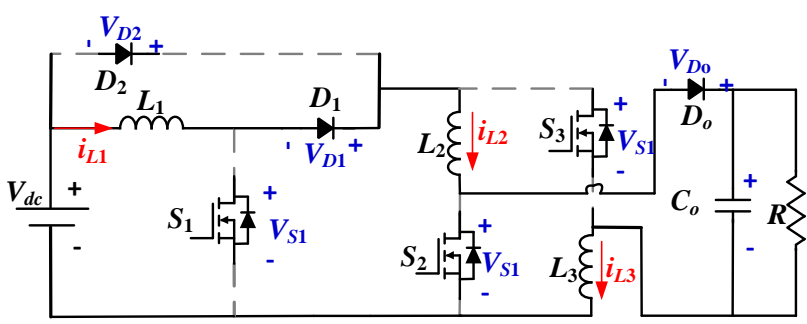

Fig.4. Configuration of Mode II.

$$
\frac{V_{o}}{V_{\text {in }}}=\frac{2(1+D)}{(1-D)}
$$

Considering inductor charge-balance and capacitor charge balance the relation between output and input 
voltage can be obtained from eq (1) and eq (2) [18].

The voltage gain of the converter is given by equation (3). Where $V_{i n}, V_{o}, V_{C 1}, D, R, v_{L 1}, v_{L 2}, i_{c o}, i_{l 1}, i_{l 2}$ are denoted to input voltage, output voltage, capacitor $C_{1}$ voltage, duty cycle, load resistance, inductor $L_{1}$ voltage, inductor $L_{2}$ voltage, capacitor $C_{o}$ current, inductor $L_{1}$ current, and inductor $L_{2}$ current, respectively.

Voltage stress of each component is depicted in Table. II. all components have voltage stress lower than the output voltage. This is the unique advantage of this topology. It enables the selection of low rating device and this improves the overall efficiency of the system.

Circuit parameter design is based on the amount of ripple desired in the inductor current and capacitor voltages. In order to maintain CCM operation inductor current ripple is designed to be small. Design of each component of the circuit is given in the upcoming sections.

Component voltage stress at different voltage gain is depicted in Fig.5. in this figure, input voltage is set to $50 \mathrm{~V}$. Diode $D_{1}$ has fixed voltage regardless of the voltage gain of the converter, while output diode is the component under the highest voltage stress.

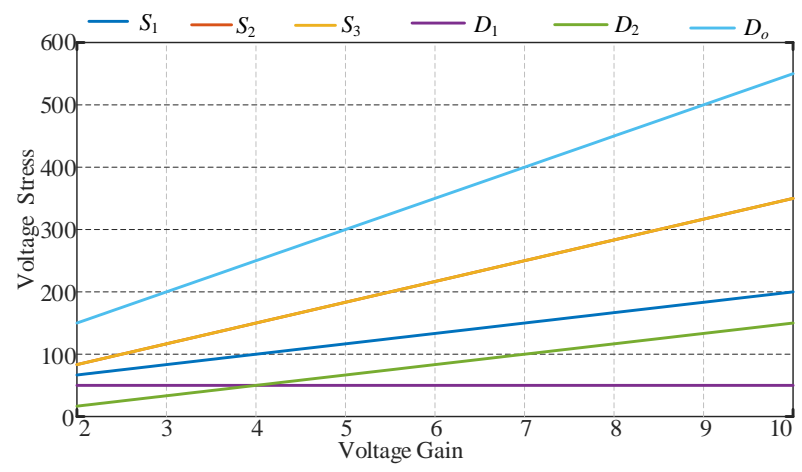

Fig.5. Component voltage stress at different voltage gain and input voltage $50 \mathrm{~V}$

\section{A. Inductor $L_{l}$ design}

the inductor current is sketched in Fig.6. During the first subinterval, the change in inductor current, $2 \Delta i_{L 1}$, is equal to the slope multiplied by the length of the subinterval value, or

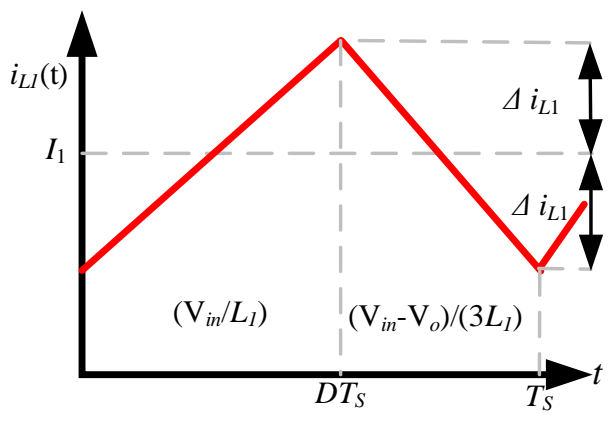

Fig.6. Inductor $L_{1}$ current.

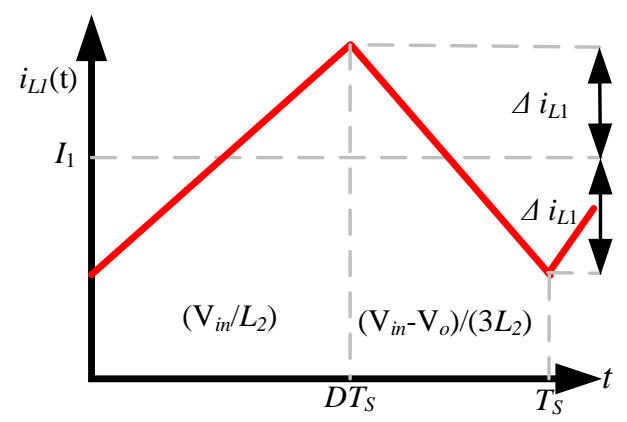

Fig.7. Inductor $L_{2}$ and $L_{3}$ currents.

$$
\begin{aligned}
& 2 \Delta i_{L 1}=\left(\frac{V_{i n}}{L_{1}}\right) D T_{S} \\
& L_{1}=\left(\frac{V_{i n}}{2 \Delta i_{L 1}}\right) D T_{S}
\end{aligned}
$$

Equation (5) is used to select the inductor $L_{1}$ value. Inductor $L_{1}$ value depends on the input voltage $V_{i n}$, duty cycle $D$, sample time $T_{S}$ and inductor current ripple $\Delta i_{L}$.

\section{B. Inductor $L_{2} \& L_{3}$ design}

the inductor current is sketched in Fig.7. During the first subinterval, the change in inductor current, $2 \Delta i_{L 2}$, is equal to the slope multiplied by the length of the subinterval value, or

$$
\begin{aligned}
& 2 \Delta i_{L 2}=\left(\frac{V_{\text {in }}}{L_{2}}\right)\left(\frac{D T_{S}}{1-D}\right) \\
& L_{2}=L_{3}=\left(\frac{V_{i n}}{2 \Delta i_{L 2}}\right)\left(\frac{D T_{S}}{1-D}\right)
\end{aligned}
$$




\section{Output capacitor Design $C_{o}$}

Likewise, the capacitor voltage waveform can be sketched and an expression derived for the output voltage ripple peak magnitude, $\Delta v_{o}$. The capacitor voltage waveform is sketched in Fig.8. The change in the capacitor voltage, $-2 \Delta v_{o}$, is equal to the slope multiplied by the length of subinterval:

$$
\begin{aligned}
& \Delta v_{o}=\left(\frac{V_{o}}{2 R C_{o}}\right) D T_{S} \\
& C_{o}=\left(\frac{V_{o}}{2 \Delta v_{o} C_{o}}\right) D T_{S}
\end{aligned}
$$

(9) is used to select output capacitor value. Its value depends on output voltage $V_{o}$, duty cycle $D$, sample time $T_{s}$ and capacitor voltage ripple $\Delta v_{o}$.

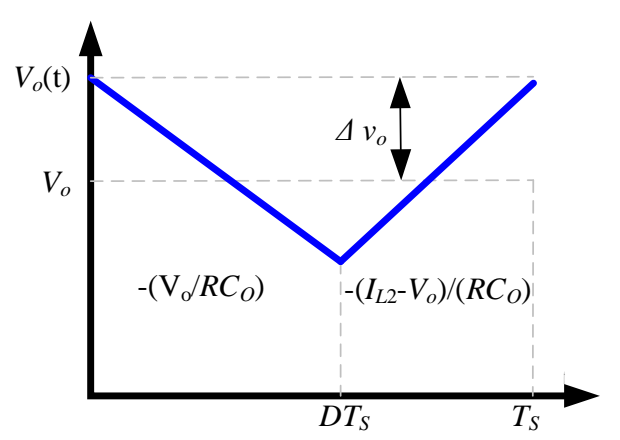

Fig.8. Capacitor Co voltage.

Voltage stress of circuit components are given in Table 1. Switched are under voltage stress lower than the output voltage, diodes D1 has voltage stress equal to the input voltage, while D2 is under stress lower than one-third of the output voltage. Output diode Do is the only circuit device which is under high voltage stress, which is common on most of the boost converters.

Table1 Topology Voltage Stresses

\begin{tabular}{ll}
\hline \hline Device & Voltage stress \\
\hline \hline$S_{1}$ & $\left(V_{o}+2 V_{i n}\right) / 3$ \\
\hline$S_{2}$ & $\left(2 V_{o}+V_{i n}\right) / 3$ \\
\hline$S_{3}$ & $\left(2 V_{o}+V_{i n}\right) / 3$ \\
\hline$D_{1}$ & $V_{\text {in }}$ \\
\hline$D_{2}$ & $\left(V_{o}-V_{i n}\right) / 3$ \\
\hline$D_{o}$ & $V_{o}+V_{\text {in }}$ \\
\hline \hline
\end{tabular}

\section{Results and discussion}

The performance of the proposed converter is verified by the experimental results based on laboratory prototype. The parameters of the proposed converter are given in Table 2 . The prototype implemented in the laboratory is illustrated in Fig.9.

Table 2 Specification of design parameters

\begin{tabular}{l|l|l}
\hline \hline$V_{\text {in }}$ & Input Voltage & $20-40 \mathrm{~V}$ \\
\hline \hline$V_{o}$ & Output Voltage & $200-450$ \\
\hline$L_{1}, L_{2}$ & Input Inductor & $3 \mathrm{mH}$ \\
\hline$C_{\text {in }}$ & Input Capacitor & $260 \mu \mathrm{F}$ \\
\hline$C_{1}$ & Parallel capacitor & $260 \mu \mathrm{F}$ \\
\hline$C_{o}$ & Output Capacitor & $260 \mu \mathrm{F}$ \\
\hline$S_{1}$ and $S_{2}$ & Power Mosfet & $I R F P 264$ \\
\hline$D_{1}, D_{2}$ & Power Diode & $B Y V 72 E W-200$ \\
\hline$D_{o}$ & Output Diode & $B Y V 72 E W-200$ \\
\hline$F_{S}$ & Switching Frequency & $10 K H_{Z}$ \\
\hline$P_{o}$ & Output Power & $150 \mathrm{~W}$ \\
\hline \hline
\end{tabular}

The three switches of the converter are triggered on and off simultaneously. Pulses applied to the three MOSFETs gate-source are depicted in Fig.10. As a result of applying symmetrical pulses to the three switches, this leads to synchronous operation of the three switches. Switches $S_{2}$ and $S_{3}$ have similar voltage stress while switch $S_{1}$ has lower voltage compared to the other switches.

The topology includes three diodes. Diode $D_{1}$ are operating simultaneously with the power MOSFETs, while $D_{2}$ and $D_{\mathrm{o}}$ are operating in complementary manner to provide a freewheeling path to the inductor current. In Fig.11, the relation between output voltage, switches $S_{1}$ and $S_{2}$ and output diode are depicted.

Two desired features for converters operating in renewable energy application; high voltage gain and maintain a moderate efficiency. Two desired features for converters operating in renewable energy application; high voltage gain and maintain a moderate efficiency. In Fig.12, the duty cycle is set to 0.35 and the voltage gain is around 2.5 times of the input voltage. Fig. 13 is a depiction of the ideal voltage-gain and measured voltage-gain. The difference between measured voltage gain and ideal voltage gain is due to the effect of copper losses and on-resistance of the MOSFETs.

The system efficiency is measured at a different point till $200 \mathrm{~W}$, with input voltage set to $20 \mathrm{~V}$ and duty cycle set to 0.7 . the converter gives efficiency around $90 \%$ as shown in Fig.14. 


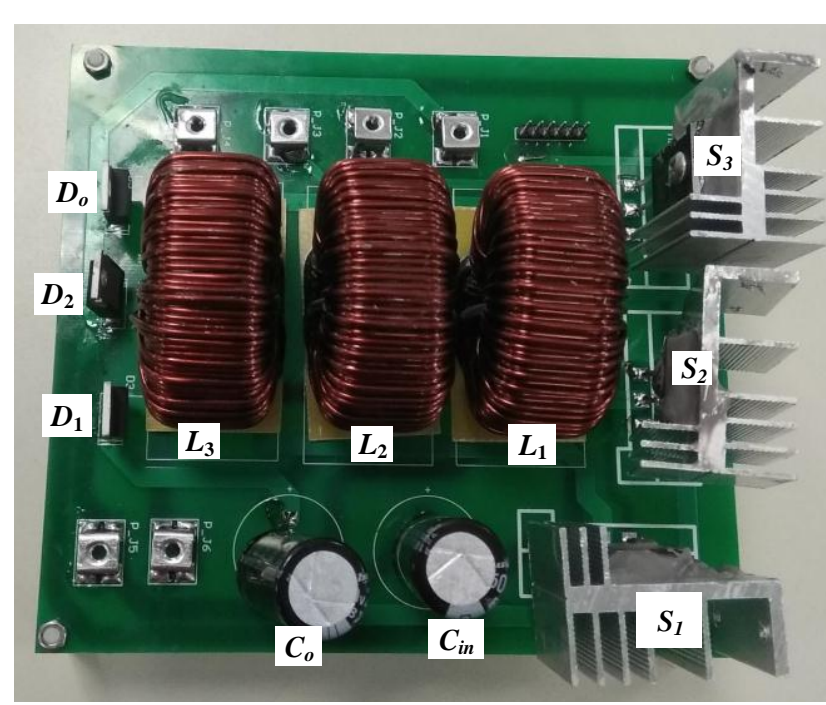

Fig.9. Hardware Photocopy.

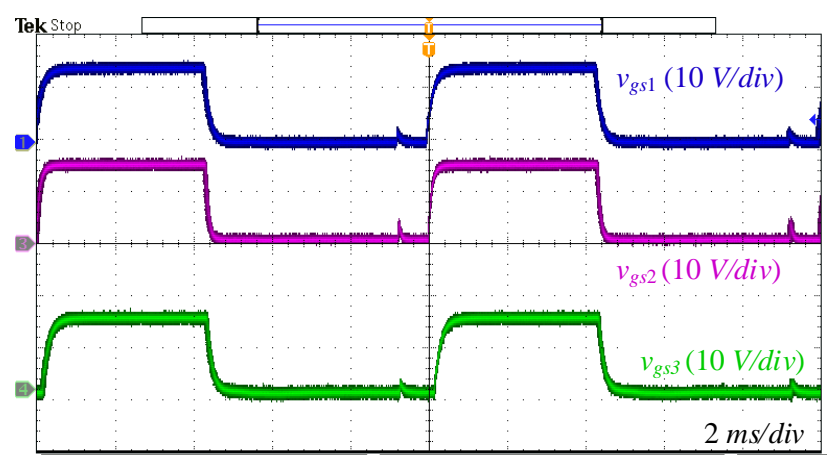

Fig.10. Converter switches pulses.

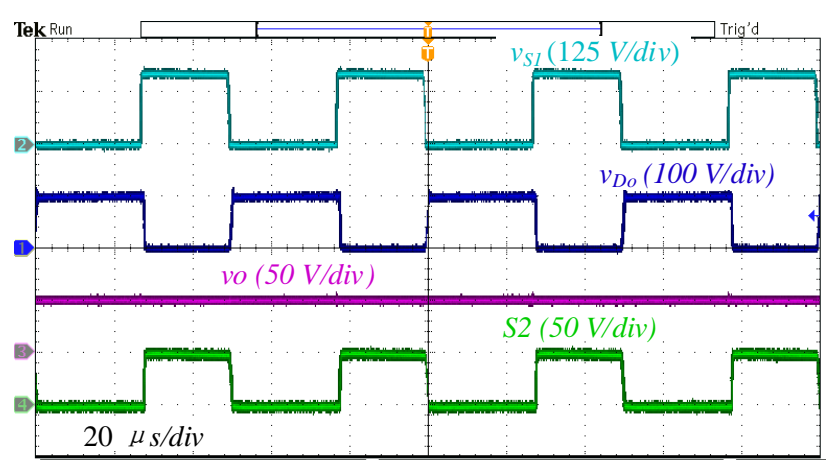

Fig.11. Switches $S_{1}$ and $S_{2}$, output diode reverse voltage and output voltage

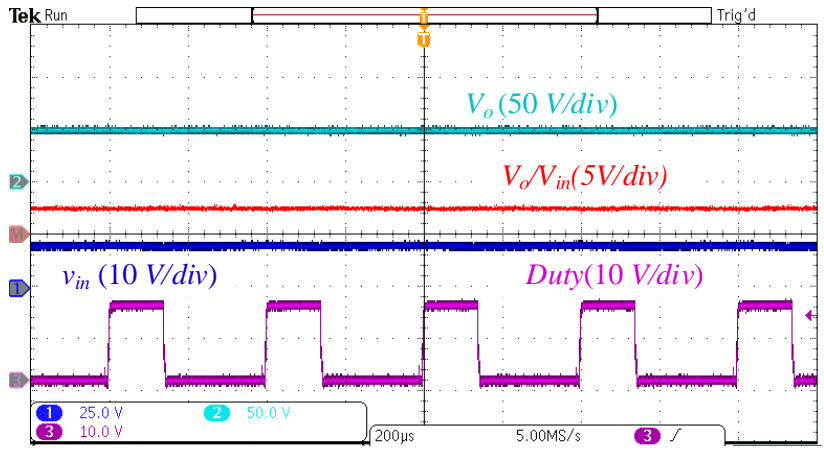

Fig.12. Case study of voltage gain of 2.5 times with duty cycle set to .35 .

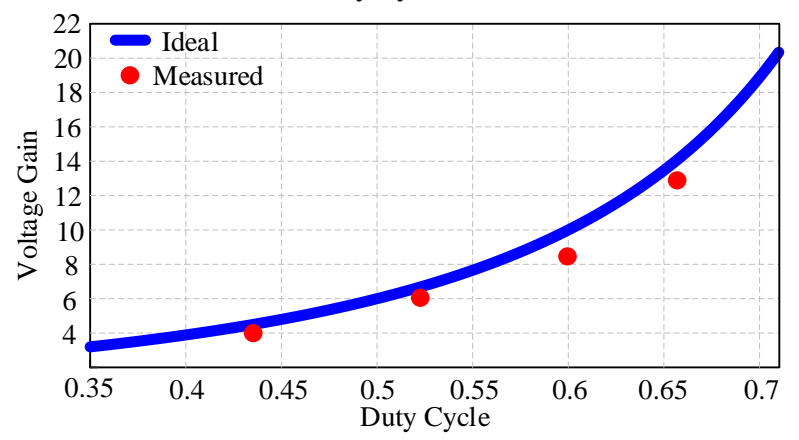

Fig.13. Ideal and measured voltage gain.

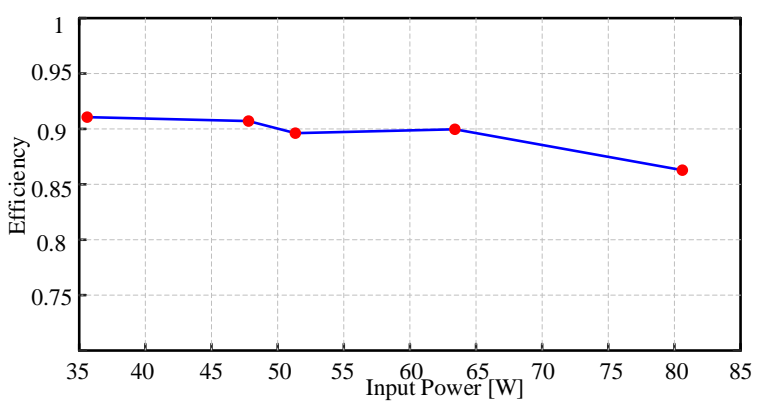

Fig.14. Measured efficiency.

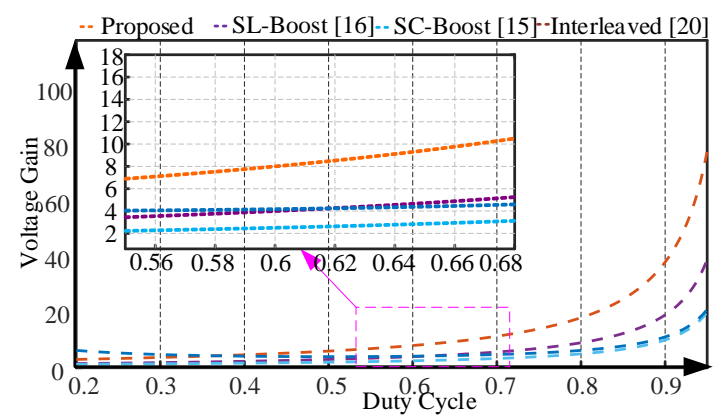

Fig.15. Voltage gain comparison among different $\mathrm{dc}-\mathrm{dc}$ step up topologies. 
Table 3 state of the art comparison

\begin{tabular}{lllllll}
\hline \hline Converter & $\begin{array}{l}\text { Switch } \\
\text { Count }\end{array}$ & $\begin{array}{l}\text { Inductor } \\
\text { Count }\end{array}$ & $\begin{array}{l}\text { Capacitor } \\
\text { count }\end{array}$ & $\begin{array}{l}\text { Diode } \\
\text { Count }\end{array}$ & Voltage gain & Voltage stress \\
\hline \hline$[29]$ & 2 & 4 & 3 & 7 & $(3+D) /(1-D)$ & $\begin{array}{l}S_{1}: 2 V /(3+D) \\
S_{2}:(1+D) /(3+D)\end{array}$ \\
\hline \hline$[30]$ & 2 & 2 & 4 & 6 & $\left(3-3 D+D^{2}\right) /(1-D)^{2}$ & $\begin{array}{l}S_{1}: V /\left(3-3 D+D^{2}\right) \\
S_{2}: V /\left(3-3 D+D^{2}\right)\end{array}$ \\
\hline \hline$[31]$ & 1 & 4 & 6 & 3 & $(3 D) /(1-D)$ & $S: V /(3 D)$ \\
\hline \hline$[32]$ & 2 & 2 & 2 & 4 & $(5+D) /(1-D)$ & $S: V /(5+D)$ \\
\hline \hline proposed & 3 & 3 & 1 & 3 & $2(1+D) /(1-D)$ & $\begin{array}{l}S_{1}:\left(V_{o}+2 V_{\text {in }}\right) / 3 \\
S_{2}:\left(2 V_{o}+V_{\text {in }}\right) / 3\end{array}$ \\
\hline \hline
\end{tabular}

Many solutions have been provided in the literature to the incorporation of PV system into existing systems. Providing high step-up capability is a mandatory characteristic for any converter are used in photovoltaic applications. Fig.15 provides a voltage gain comparison between the proposed topology and other transformerless topologies exist in the literature. The graph is plotting the voltage gain of all converters with duty cycle varying duty cycle. The traditional boost converter has the minimum boosting capability among all presented converters, while proposed converter has the highest gain among different topologies. A comparison in point of view parameter counts and parameter stress is illustrated in Table 3.

\section{Conclusion}

This article focuses on developing high-gain transformerless $\mathrm{dc} / \mathrm{dc}$ converter for renewable energy applications. A new step-up configuration has been presented. The developed configuration featured high step-up ability with acceptable efficiency. Principle of operation, analytical analysis of the converter is illustrated and studied in detail. Laboratory prototype has been implemented. Different cases of studies have been studied to validate the boosting ability and efficiency of the converter. A comprehensive comparison between the proposed configurations and other transformerless topologies exist in the literature. Experimental results comply with the theoretical analysis.

\section{References}

[1]. Marroqui, David, Ausias Garrigós, Cristian Torres, Carlos Orts, Jose M. Blanes, and Roberto Gutierrez. 2021. "Interleaved, Switched Inductor and High-Gain Wide Bandgap Based Boost Converter Proposal" Energies14, no. 4: 800.
[2]. O. Abdel-Rahim and H. Wang, "A new high gain DC-DC converter with model-predictive-control based MPPT technique for photovoltaic systems," in CPSS Transactions on Power Electronics and Applications, vol. 5, no. 2, pp. 191-200, June 2020, doi: 10.24295/CPSSTPEA.2020.00016.

[3]. A. Gupta, R. Ayyanar and S. Chakraborty, "Non-isolated High Gain Boost Converter Operating in Critical Conduction Mode," 2019 IEEE Energy Conversion Congress and Exposition (ECCE), 2019, pp. 4754-4759, doi: 10.1109/ECCE.2019.8913188.

[4]. T. Chen, O. Abdel-Rahim, F. Peng and H. Wang, "An Improved Finite Control Set-MPC-Based Power Sharing Control Strategy for Islanded AC Microgrids," in IEEE Access, vol. 8, pp. 52676-52686, 2020, doi: 10.1109/ACCESS.2020.2980860.

[5]. Loranca-Coutiño, Javier, Carlos A. Villarreal-Hernandez, Jonathan C. Mayo-Maldonado, Jesús E. Valdez-Resendiz, Adolfo R. Lopez-Nuñez, Omar F. Ruiz-Martinez, and Julio C. Rosas-Caro 2020. "High Gain Boost Converter with Reduced Voltage in Capacitors for Fuel-Cells Energy Generation Systems" Electronics 9, no. 9: 1480.

[6]. B. P. R. Baddipadiga, V. A. K. Prabhala and M. Ferdowsi, "A Family of High-Voltage-Gain DC-DC Converters Based on a Generalized Structure," in IEEE Transactions on Power Electronics, vol. 33, no. 10, pp. 8399-8411, Oct. 2018, doi: 10.1109/TPEL.2017.2777451.

[7]. O.Abdel-Rahim, H. Abu-Rub, A. Kouzou,"Nine-to-Three Phase Direct Matrix Converter with Model Predictive Control for Wind Generation System," Energy Procedia, Vol 42, 2013, Pp 173-182

[8]. Z. W. Khan, H. Minxiao, C. Kai, L. Yang and A. u. Rehman, "State of the Art DC-DC Converter Topologies for the Multi-Terminal DC Grid Applications: A Review," 2020 IEEE International Conference on Power Electronics, Smart Grid and Renewable Energy (PESGRE2020), 2020, pp. 1-7, doi: 10.1109/PESGRE45664.2020.9070529.

[9]. O. Abdelrahim, H. Funato" A comprehensive study of three high-gain DC-DC topologies based on Cockcroft-Walton voltage multiplier for reduced power PV applications" IEEJ Transactions on Electrical and Electronic Engineering, vol:13 iss:4 pg:642 -651

[10].M. Forouzesh, Y. P. Siwakoti, S. A. Gorji, F. Blaabjerg and B. Lehman, "Step-Up DC-DC Converters: A Comprehensive Review of Voltage-Boosting Techniques, Topologies, and Applications," in IEEE Transactions on Power Electronics, vol. 32, no. 12, pp. 9143-9178, Dec. 2017, doi: 10.1109/TPEL.2017.2652318.

[11].O. Abdel-Rahim, M. Orabi and M. E. Ahmed, "Buck-boost interleaved inverter for grid connected Photovoltaic system," 2010 
IEEE International Conference on Power and Energy, 2010, pp. 63-68.

[12].Y. Guan, C. Cecati, J. M. Alonso and Z. Zhang, "Review of High-Frequency High-Voltage-Conversion-Ratio DC-DC Converters," in IEEE Journal of Emerging and Selected Topics in Industrial Electronics, vol. 2, no. 4, pp. 374-389, Oct. 2021, doi: 10.1109/JESTIE.2021.3051554.

[13].S. Khan et al., "A New Transformerless Ultra High Gain DC-DC Converter for DC Microgrid Application," in IEEE Access, vol. 9, pp. 124560-124582, 2021, doi: 10.1109/ACCESS.2021.3110668.

[14].Abdel-Rahim, Omar, Nehmedo Alamir, Mohamed Abdelrahem, Mohamed Orabi, Ralph Kennel, and Mohamed A. Ismeil 2020. "A Phase-Shift-Modulated LLC-Resonant Micro-Inverter Based on Fixed Frequency Predictive-MPPT" Energies 13, no. $\quad$ 6: 1460 https://doi.org/10.3390/en13061460

[15].A. Alzahrani, M. Ferdowsi and P. Shamsi, "A Family of Scalable Non-Isolated Interleaved DC-DC Boost Converters with Voltage Multiplier Cells," in IEEE Access, vol. 7, pp. 11707-11721, 2019.

[16].M. Forouzesh, Y. Shen, K. Yari, Y. P. Siwakoti and F. Blaabjerg, "High-Efficiency High Step-Up DC-DC Converter with Dual Coupled Inductors for Grid-Connected Photovoltaic Systems," in IEEE Transactions on Power Electronics, vol. 33, no. 7, pp. 5967-5982, July 2018, doi: 10.1109/TPEL.2017.2746750.

[17].O.Abdelrahim, h. Funato" An Efficient and High-gain Inverter Based on The 3S Inverter Employs Model Predictive Control for PV Applications" Journal of Electrical Engineering and Technology, Vol 12, Issue 4, Pp.1484-1494

[18].A. Kumar and P. Sensarma, "Ripple-Free Input Current High Voltage Gain DC-DC Converters with Coupled Inductors," in IEEE Transactions on Power Electronics, vol. 34, no. 4, pp. 3418-3428, April 2019, doi: 10.1109/TPEL.2018.2854778.

[19].Y. Ye, J. Lin, Z. Li and X. Wang, "Double-Tiered Cell Balancing System with Switched-Capacitor and Switched-Inductor," in IEEE Access, vol. 7, pp. 183356-183364, 2019, doi: 10.1109/ACCESS.2019.2960093.

[20].O. Abdel-Rahim, M. Orabi, E. Abdelkarim, M. Ahmed and M. Z. Youssef, "Switched inductor boost converter for PV applications," 2012 Twenty-Seventh Annual IEEE Applied Power Electronics Conference and Exposition (APEC), 2012, pp. 2100-2106, doi: 10.1109/APEC.2012.6166111

[21].M. Uno and A. Kukita, "PWM Switched Capacitor Converter With Switched-Capacitor-Inductor Cell for Adjustable High Step-Down Voltage Conversion," in IEEE Transactions on Power Electronics, vol. 34, no. 1, pp. 425-437, Jan. 2019, doi: 10.1109/TPEL.2018.2822344.

[22].C. -Y. Chan, S. Chincholkar and W. Jiang, "A Modified Fixed Current-Mode Controller for Improved Performance in Quadratic Boost Converters," in IEEE Transactions on Circuits and Systems II: Express Briefs, vol. 67, no. 10, pp. 2014-2018, Oct. 2020, doi: 10.1109/TCSII.2019.2942057.

[23].O. Abdel-Rahim and H. Furiato, "Switched inductor quadratic boosting ratio inverter with proportional resonant controller for grid-tie PV applications," IECON 2014 - 40th Annual Conference of the IEEE Industrial Electronics Society, 2014, pp. 5606-5611, doi: 10.1109/IECON.2014.7049358.

[24].V. F. Pires, A. Cordeiro, D. Foito and J. F. Silva, "High Step-Up DC-DC Converter for Fuel Cell Vehicles Based on Merged Quadratic Boost-Ćuk," in IEEE Transactions on Vehicular Technology, vol. 68, no. 8, pp. 7521-7530, Aug. 2019, doi: 10.1109/TVT.2019.2921851.

[25].J. Liu, J. Wu, J. Qiu and J. Zeng, "Switched Z-Source/Quasi-Z-Source DC-DC Converters with Reduced Passive Components for Photovoltaic Systems," in IEEE Access, vol. 7, pp. 40893-40903, 2019, doi: 10.1109/ACCESS.2019.2907300.

[26].M. Gaber, O. Abdel-Rahim and M. Orabi, "Optimization of the Modulation Sequence and Proposing an Overlap Technique for Current Source Inverter," 2019 IEEE Applied Power Electronics Conference and Exposition (APEC), 2019, pp. 2475-2480, doi: 10.1109/APEC.2019.8722210.

[27].M. M. Haji-Esmaeili, E. Babaei and M. Sabahi, "High Step-Up Quasi-Z Source DC-DC Converter," in IEEE Transactions on Power Electronics, vol. 33, no. 12, pp. 10563-10571, Dec. 2018, doi: 10.1109/TPEL.2018.2810884.

[28].J. Imaoka, K. Okamoto, M. Shoyama, M. Noah, S. Kimura and M. Yamamoto, "A high-reliable magnetic design method for three-phase coupled inductor used in interleaved multi-phase boost converters," 2017 IEEE Energy Conversion Congress and Exposition (ECCE), 2017, pp. 873-880, doi: 10.1109/ECCE.2017.8095877.

[29].S. Khan, A. Mahmood, M. Tariq, M. Zaid, I. Khan, and S. Rahman, "Improved dual switch non-isolated high gain boost converter for DC microgrid application," in Proc. IEEE Texas Power Energy Conf. (TPEC), Feb. 2021, pp. 1_6.

[30].A. Kumar, Y. Wang, X. Pan, M. Raghuram, S. K. Singh, X. Xiong, and A. K. Tripathi, "Switched-LC based high gain converter with lower component count," IEEE Trans. Ind. Appl., vol. 56, no. 3, pp. 2816_2827, May 2020.

[31].M. R. Banaei and S. G. Sani, “Analysis and implementation of a new SEPIC-based single-switch buckboost DC-DC converter with continuous input current," IEEE Trans. Power Electron., vol. 33 , no. 12 , pp. 10317,10325 .

[32].S. Khan, M. Zaid, A. Mahmood, J. Ahmad, and A. Alam, “A single switch high gain DC-DC converter with reduced voltage stress," in Proc. IEEE 7th Uttar Pradesh Sect. Int. Conf. Electr., Electron. Comput. Eng. (UPCON), Nov. 2020, pp. 1-6. 